\title{
CONSIDERAÇÕES PARA A EDUCAÇÃO NO TRÂNSITO
}

\author{
Nicolau Ayres \\ Lúcia Maria Gomes Corrêa Ferri \\ Programa de Mestrado em Educação - Universidade do Oeste Paulista - UNOESTE
}

Recebido em: 27/05/2002

Aceito em: $24 / 05 / 2004$

RESUMO: O novo Código de Trânsito Brasileiro, Lei 9503 de 23 de Setembro de 1997, estabeleceu, em seu artigo 76 , que a educação para o trânsito será promovida na pré-escola e nas escolas de $1^{\circ}, 2^{\circ}$ e $3^{\circ}$ graus. Nossas autoridades através dessa lei, tentam minimizar um problema social grave, que se alastra por todo o país. Pretendem estas considerações colaborar com a sociedade civil, buscando respostas para o problema.

PALAVRAS-CHAVE: trânsito; tráfego; educação.

\section{CONSIDERATION FOR THE EDUCATION IN THE TRANSIT}

ABSTRACT: The new Code of Brazilian Transit, Law 9503 of 23 of September of 1997, established, in its article 76 , that the education for the transit will be promoted in the daily pay school and the schools of $1^{\circ}, 2^{\circ}$ and $3^{\circ}$ degrees. Our authorities through this law, try to minimize serious a social problem, that if spreads all over the country. They intend these consideration to collaborate with the civil society, searching responses for the problem.

KEY WORDS: transit; traffic; education.

\section{INTRODUÇÃO}

A educação para o trânsito é exigência da nova lei do Código de Trânsito Brasileiro e faz-se necessário a elaboração de projeto pedagógico, com programas e atividades curriculares, sobre o tema que indaguem, o que, quando, como ensinar e avaliar educação para o trânsito.

Faz-se necessário um parêntese para apresentação Código de Trânsito Brasileiro - Lei 9.503, de 23 de setembro de 1997, em matéria específica do assunto.

Artigo 76 - A educação para o trânsito será promovida na pré-escola e nas escolas de $1^{\circ}, 2^{\circ}$ e $3^{\circ}$ graus, através de planejamento e ações coordenadas entre órgãos e entidades do sistema Nacional de Trânsito e de Educaşão, da União, dos Estados, do Distrito Federal e dos Municípios, nas respectivas áreas de atuação.

Parágrafo único. Para a finalidade prevista neste artigo, o Ministério da Educação e do Desporto, mediante proposta do CONTRAN e do Conselho de Reitores das Universidades brasileiras, diretamente ou mediante convênio promoverá:

I - a adoção em todos os niveis de ensino de um currículo interdisciplinar com conteúdo programático sobre segurança de trânsito;

II - a adoção de conteúdos relativos à educação para o trânsito nas

\footnotetext{
* Correspondência:
}

E-mail: Imcayres@aol.com 


\author{
escolas de formação para o magistério e o treinamento de professores \\ e multiplicadores; \\ III - a criação de corpos técnicos interprofissionais levantamento e \\ análise de dados estatísticos relativos ao trânsito; \\ IV - a elaboração de planos de redução de acidentes de trânsito junto \\ aos núcleos interdisciplinares universitários de trânsito com vistas à \\ integração universidades - sociedades na área de trânsito.
}

O artigo 315 da supra citada lei enfatiza:

\section{O Ministério da Educação e do Desporto mediante proposta do CONTR AN deverá, no prazo de duzentos e quarenta dias contados da publicação desta lei, estabelecer o currículo com conteúdo programático relativo à segurança e educação de trânsito, a fim de atender, o disposto neste Código.}

Coll (1996, p. 44 - 46) nos apresenta uma proposta para o currículo.

Enquanto projeto, o currículo é um guia para os encarregados de seu desenvolvimento, um instrumento útil para orientar a prática pedagógica, uma ajuda para o professor. Os componentes do currículo, isto é, os elementos que ele contempla para cumprir com êxito suas funções, podem agrupar-se desta forma, informações sobre o que ensinar.

Neste enfoque inclui: conteúdos (termo que designa aqui, em sua acepção mais ampla, o que chamamos de "a experiência social culturalmente aceita”: conceitos, sistemas explicativos, habilidades, normas, valores e objetivos (os processos de crescimento pessoal que se deseja provocar, favorecer ou facilitar o ensino). A experiência social, culturalmente tolerada sobre o comportamento de pessoas no trânsito, não é das melhores, pois, temos a impressão que o desrespeito as normas estabelecidas são recidivas, conforme observamos pelos noticiários diários.

A educação formal abrange, com efeito, conteúdos complexos e inter-relacionados e pretende incidir sobre diversos aspectos do crescimento pessoal do aluno, sendo necessário, portanto, optar por uma determinada seqüência de ação. A nova lei do trânsito estabelece que a educação para o trânsito será promovida na pré-escola e nas escolas de $1^{\circ}, 2^{\circ}$ e $3^{\circ}$ graus. É claro e evidente que, a educação para o trânsito terá uma linguagem própria, conforme a faixa etária e escolaridade dos alunos.

Como ensinar, isto é, sobre a maneira de estruturar as atividades de ensino e aprendizagem das quais participarão os alunos, a fim de atingir os objetivos propostos em relação aos conteúdos selecionados. Sobre o elemento proposto, como ensinar, em se tratando de educação para o trânsito, seria conveniente, além das aulas teóricas, fossem incluídas aulas práticas de comportamento no trânsito, como já vem sendo feito de modo esporádico em algumas escolas. Na medida em que o projeto corresponde a certas intenções, a avaliação é um elemento indispensável que assegura se a ação pedagógica responde adequadamente às mesmas e introduz as correções oportunas em caso contrário.

A avaliação vai nos revelar se houve algum aproveitamento dos ensinos ministrados aos alunos e, ao mesmo tempo, se o método tem correspondido à proposta inicial.

O planejamento e desenvolvimento de um currículo são fatores fundamentais para que possamos responder às seguintes indagações: o que, quando, como ensinar e avaliar.

As origens do emprego do termo currículo, faz notar sua ligação às idéias de unidade, ordem seqüência dos elementos de um curso, e, a elas subjacentes, as aspirações de se imprimir maior rigor à organização do ensino. Associa-se, portanto, à idéia de formalização, envolvendo plano, método e avaliação.

SAVIANI (1994, p.40-44). Registra o surgimento do uso do termo no final do século XVI, mais especificamente com o Calvinismo. Possivelmente, o termo teria sido utilizado em 1582, nas escriturações da Universidade de Leiden (Holanda), mas o primeiro registro que dela se constata e, segundo o Oxford English Dictionary, o de um atestado de graduação outorgado a um mestre da Universidade de Glasgow (Escócia) em 1663.

Essas Universidades tinham estrita ligação com as idéias Calvinistas, pois possuíam o propósito de formar "pregadores" protestantes. Integravam-se ao movimento pela reforma da agenda educativa medieval, visando a propagação de novos pressupostos sobre a eficiência da escolarização, em particular e, da sociedade, em geral. Neste mesmo período, encontrava-se a referência ao termo para registrar um curso multianual total seguido por cada estudante ou o Curriculum 
Vitae, do estudante num curso.

O termo latino que significa movimento progressivo ou carreira, para uma entidade educativa que denotava uma totalidade estrutural e uma integridade seqüencial formando um todo unitário que devia, não apenas ser seguido, mas também acabado. O termo currículo foi ganhando riqueza semântica e multiplicidade de usos no vocabulário inglês, mais do que em outros idiomas. No vocabulário inglês, currículo passou a significar uma abordagem global dos fenômenos educativos, o privilegiamento dos conteúdos e de sua organização nos cursos.

A idéia de currículo faz-se acompanhar pela ordem e disciplina no sentido de seqüência interna; disciplina no sentido de coerência estrutural, como elementos indispensáveis a qualquer curso. O que predominou nos debates educativos do século XVI, foi o método: como uma ciência intencional da técnica, com linhas mestras que pudessem ser rapidamente assimiladas e facilmente aplicadas.

O método equivalia a um conjunto de procedimentos padronizados, destinados a ensinar fácil e claramente qualquer matéria.

À idéia de currículo soma-se a de:

Ordenação: que implica metodiæação no sentido de formalização. O ensino adquiriria maior força ou eficiência se formalizasse, regularidade e centralidade, inerentes ao preceito calvinista de disciplina, como regra de vida, sendo o elemento de coesão da escola.

O ensino passaria a seguir um plano rígido, compreendendo as áreas de estudo a que se dedicaria cada professor e às normas de conduta do aluno, cuja promoção de um nível a outro do curso dependeria dos progressos nos estudos e do cumprimento às normas estabelecidas e cuja vida estudantil estaria sob a supervisão do professor.

O nome dado, certificado de conclusão do curso, com a avaliação dos resultados de cada estudante, era o currículo que representava todo esse conjunto. Então vemos que a idéias inicial de currículo era o registro da vida estudantil de cada aluno.

Existe, ainda, muita discussão em torno do assunto currículo As pessoas procuram se adequar, de acordo com a realidade em que vivem, procurando um caminho, uma forma, uns meios, de melhor transmitir os preceitos básicos, onde estes sejam apenas ponto de partida, para um aprofundamento cultural e técnico em todos os segmentos da sociedade. O currículo, por sua vez, não deve desassociar-se da realidade presente.

Rozestratem (1998, p.48-49), afirma que:

“...já se deixou claro que qualquer educação, para ter sucesso, necessita seguir as normas pedagógicas básicas, assim como qualquer ensino necessita seguir as normas da didática. A modificação do comportamento no trânsito, das diversas gerações, presentes na sociedade, depende muito de uma educação adequada, o que, por sua vez, depende de um material didático disponivel que possa ser manuseado facilmente pelos professores."

$\mathrm{Na}$ realidade existem diversas teorias a respeito de currículo e até algumas bastantes antagônicas entre si. Constatamos que não existe ainda, experiências sistemáticas e avaliadas, que atendam à educação para o trânsito, o que existe são iniciativas isoladas por parte de algumas escolas ou órgão. Daí resulta a importância da elaboração de currículo e de programas que atendam às necessidades prioritárias de um bom ensino nas escolas, evidenciando-se todos os aspectos do trânsito e, como conseqüência, o comportamento do pedestre e do motorista.

Tendo em vista, nos termos da nova lei de trânsito, a obrigatoriedade da educação para o trânsito nas escolas, deve-se pensar e elaborar currículos que atendam às necessidades dos alunos.

Saviani (1994, p.45), apresenta-nos as dificuldades para a elaboração de um currículo, referindo-se as fontes e aos componentes curriculares, conforme o elenco adiante apresentado:

"A legislação e documentos oficiais - as peças de interpretạ̧ão da legislação - o registro do rol de matérias escolares - a grade curricular comuns e específicos - a documentação da vida estudantil - funçöes legais e características do corpo docente - programas de aperfeiçoamento de professores e especialistas - livros e meios didáticos e sua aplicação em sala de aula."

O currículo não deve estar distanciado da realidade social da época em que se vive, o nível de plano do ensino importa determinar o sistema de avaliação, já discriminado e operacionalizado em conformidade com o programa a ser elaborado, sem se afastar dos princípios e dos objetivos enunciados pelas normas vigentes. 
Sant'anna et all (1992, p.59), afirma: "Divergem as opiniões sobre onde buscar as bases para a adoção de decisões sobre os objetivos da escola e do professor. Não há uma fonte única, já que cada uma e todas possuem valores e por isso devem ser consideradas.”

Na elaboração do currículo, um fator importante é a organização dos conteúdos de ensino. Podemos considerar a aprendizagem num determinado campo do conhecimento como resultado de uma interação entre processos mentais e elementos cognitivos selecionados sobre a base de certos princípios. O aluno poderá atingir bom nível de rendimento, quando possuir as compreensões e os conhecimentos básicos da estrutura da disciplina e um domínio funcional de seus princípios e generalizações.

Constatamos que não existe uma concordância sobre o assunto entre os autores, pois a matéria é ampla e empolgante sob o ponto de vista teórico. Os estudiosos da organização dos conteúdos de ensino intensificam suas discussões sobre as questões ali colocadas, sendo que o questionamento sempre gira em torno de qual tecnologia, deve ser adotada para que se tenha resultado eficaz.

Muitas vezes, esses questionamentos nos mostram que determinados conteúdos são dispensáveis e poderão ser substituídos por outros mais atuais e de acordo com a nova realidade que se apresenta.

Não podemos nos esquecer que existe em determinados grupos de pessoas, modos reiterados de procedimentos, constituindo-se em verdadeiras "leis" entre esses grupos. Essas culturas, agregadas a determinados grupos, tendem a se expandir formando um costume que adquire força pela sua continuidade, passando a integrar-se entre as pessoas como se fosse uma lei, ou seja, de forma consuetudinária, convém observar-se tais costumes ao se elaborar um programa ou um currículo voltado para a educação para o trânsito. A política de uma nação está intimamente ligada com a cultura de sua sociedade, constituindo-se numa força e também perpetuando valores hegemônicos.

Vários grupos de pessoas, ao longo do tempo, denunciaram os problemas do trânsito, através dos meios de comunicação e apresentaram diversos tipos de propostas, inclusive que se promovesse a educação para o trânsito nas escolas.

Sobre a problemática do trânsito, houve protestos, gerando tensões e conflitos. Esses acontecimentos, de uma certa forma, ajudaram a formar a convicção de que alguma coisa deveria ser feito, culminando com a presente proposta, atualmente, artigo de lei, da necessidade de se ensinar trânsito nas escolas. O próximo passo é a elaboração de um currículo adequado para que se possa atender à educação para o trânsito. Porém, deve-se deixar claro que toda sociedade deverá estar comprometida com esta educação, a família, as instituições e agências sociais como a igreja, os meios de comunicação. A educação escolar é de grande importância para a resolução do problema, porém, sozinha não assegurará sua resolução.

Na elaboração do currículo, convém observar o grau de conhecimento que aquela população de alunos a quem vai ser dirigida a programação possui, e que evidenciará a sua forma de percepção das coisas como um todo. Alguns autores dirigiram seus estudos nesse sentido.

Assim, Penteado apud ausubel (1980, p.59), em seus estudos, considerou: "Se en tivesse que reduzir toda a Psicologia da Educação a um único princípio, en formularia este: de todos os fatores que influenciam a aprendizagem, o mais importante consiste no que o aluno já sabe. Investigue-se isso e ensine-se ao aluno de uma forma conseqüente."

Para que possamos entender o modelo de ensino proposto por David Ausubel, é necessário que se tome por base dois conceitos que, segundo o autor, são a base de sua proposta, ou seja, Estrutura Cognitiva e Aprendiragem Significativa. A estrutura cognitiva existente, tanto o conjunto de idéias presentes num indivíduo, bem como suas propriedades organizacionais, num assunto específicas, num determinado momento, são o principal fator que influência a aprendizagem.

Se o aluno tiver a estrutura cognitiva organizada e adequada, numa determinada matéria (assunto), o aprendizado, num novo assunto, será bem mais fácil. Caso contrário o aprendizado será dificultoso. Note que isso não ocorre somente nas disciplinas de $1^{\circ}$ e $2^{\circ}$ graus, mas também durante o curso na universidade. Finalmente, a experiência curricular a ser elaborada como proposta para que se promova a educação para o trânsito nas escolas é uma inovação e, como tal, nos afirma Weber (1974), enfrentará resistências, tendo em vista que a ação social cotidiana é impregnada da tradição.

Os acidentes de trânsito, ao longo dos anos, produziu, além de muito infortúnio, pressão social que resultaram medidas legais como a na inserção do artigo na nova lei do trânsito que torna obrigatória as aulas de educação para o trânsito.

Huberman (1973, p. 40), afirma categoricamente: "Resistência do ambiente às mudanças. A comunidade em geral não encoraja ou, via de regra, não conta com a mudança no sistema escolar a menos que uma crise se faça sentir em seu funcionamento interno"

As mudanças implicam em novos conceitos, atitudes, habilidades, avaliações. Trata-se de um processo que necessita ser planejado; criado e conceptualizado dentro de balizamentos que consubstanciem diretrizes, em relação ao trânsito 
automotivo. As primeiras preocupações devem ser os objetivos que levam a educação para o trânsito como um guia de comportamento educacional.

\section{VALORES E CONDUTA ÉTICA}

A educação é uma das bases fundamentais para que se desenvolva o comportamento adequado ao trânsito, evitando os acidentes com vítimas. A educação das pessoas está diretamente ligada à sua consciência de valores.

"Somente um homem educado pela consciência dos valores é que pode servir de pedra fundamental da harmonia social e da paz. mundial." (ROHDEN, 1988, p.47)

A ética relaciona-se intimamente com os valores da conduta humana, exteriorizando as ações do comportamento das pessoas. A família influi de forma preponderante na formação desses valores e da ética. Não se pode responsabilizar só a escola como formadora de valores e ética.

A tarefa de ensinar a como se comportar no trânsito e formar atitudes éticas, não é fácil. Os veículos de comunicação, ao longo do tempo projetaram imagens negativas sobre o mesmo; os noticiários diários mostram os inúmeros acidentes registrados em nossas rodovias e, também, nas vias urbanas. É fato público e notório e não precisa ser provado. A realidade é que quando ouvimos alguma notícia relacionada com o trânsito, já de imediato vemos, em nossa mente, imagem negativa. Os comportamentos positivos não são incentivados.

Os pedestres também são responsáveis pelos acidentes de trânsito, muitas vezes, ao cruzarem a pista de rolamento, eles não tomam as devidas precauções de segurança, não levam em conta a visibilidade, a distância e a velocidade dos veículos e, na maioria das vezes, não atravessam a faixa destinada a eles.

Convém lembrar que, o pedestre que atravessa a rua sobre a faixa de segurança, tem prioridade sobre os veículos. O novo Código de Trânsito equipara o condutor de veículo não motorizado, igual ao pedestre quando estiver desmontado, é o caso do ciclista.

O novo Código de Trânsito Brasileiro dedica os artigos 68 a 71 para regular a conduta do pedestre. Vamos destacar o caput do artigo 69: "Para cruzar a pista de rolamento o pedestre tomará precaucões de segurança, levando em conta, principalmente, visibilidade, a distância e a velocidade dos veiculos, utilizando sempre as faixas ou passagens a ele destinadas sempre que estas existirem numa distância de até 50 metros dele, ..."

O mundo dos valores é amplo e o que oferece os maiores graus de dificuldades para que possamos entendê-lo. Aparentemente, os valores, se nos apresentam de uma forma simples, a primeira vista, porém, à medida que pretendemos aprendê-los, eles se tornam difíceis e complexos.

Boochenski (1977, p.71-72), afirma:

"Considerando as diferentes espécies de valores, temos no campo espiritual pelo menos três séries de valores: os valores morais, os estéticos e os valores religiosos. Os valores morais são determinados pela ação, ou seja, deverfazer. E o valor que foi melhorpesquisado pelos filósofos. Os valores estéticos dizem respeito ao belo, ao elegante, ao rude. Os valores religiosos são bem conhecidos

do homem. De uma forma ou de outra, todos somos religiosos, é uma análise muito difícil de se fazer. Ela parte de um sentimento interno de cada um de nós."

Quando estudamos valor, pensamos logo em sua conceituação. O que é valor?

Diniz (1998, p.694), na composição de seu Dicionário coletou os seguintes conceitos sobre 'Valor':

vive.

Dentre os vários conceitos e formas de valores existentes, devemos ressaltar alguns que são de fundamental importância para o ser humano e, nesse sentido, destacamos as conceituações abaixo:

"Identificamos três princípios éticos que são expressão do pensar e agir moralmente. A dignidade da pessoas humana é um principio inviolável seja em que circunstância for e encontra expressões em quatro valores que consideramos básicos. Chamamo-lhes básicos porque são valores primeiros que precedem outros quando um sujeito se vê perante uma escolha moral. O direito à vida, a igualdade perante a lei, a tolerância e os direitos civis quando violados põem em causa a própria dignidade da pessoa humana." (MARQUES, 1997, p.52) 
Filosofia Geral: a) Qualidade real de certos objetos on coisas; b) idéia; c) objeto de uma experiência e de uma vivência (Hessen); d) qualidade de uma coisa que sópode pertencer-lhe em função de um sujeito dotado com uma certa consciência capaz de a registrar (Hessen). O valor é sempre valor para o sujeito. A referência a um sujeito é da essência do valor; e) características do ser que é estimado mais ou menos por um grupo; f) finalidade intrínseca do ser (Othon Sidou; g) a conformidade, a coincidência do gesto, da atitude com os fins do ser (Armando Câmara)."

Em nossas considerações, não vamos estudar valor sob a ótica da economia política, mas sim, sob o ordenamento filosófico, pois estarão voltadas para o campo dos valores morais, éticos e as atitudes do ser humano, já que pretendemos estabelecê-lo dentro de uma perspectiva humanística e cultural e, estabelecendo relações entre o valor, e, as atitudes que o ser humano desenvolve com o meio em que vive.

Dentre os vários conceitos e formas de valores existentes, devemos ressaltar alguns que são de fundamental importância para o ser humano e, nesse sentido, destacamos:

"Identificamos três princípios éticos que são expressão do pensar e agir moralmente. A dignidade da pessoas humana é um principio inviolável seja em que circunstância for e encontra expressões em quatro valores que consideramos básicos. Chamamo-lhes básicos porque são valores primeiros que precedem outros quando um sujeito se vê perante uma escolha moral. O direito à vida, a igualdade perante a lei, a tolerância e os direitos civis quando violados põem em causa a própria dignidade da pessoa bumana."(MARQUES, 1997, p.52)

Segundo Marques (1997, p.52-53), na realidade, todos gostariam de ser tratados de uma forma recíproca. A reciprocidade é um principio ético, ou seja, se respeitamos nosso próximo, gostaríamos também, de ser respeitados. A cooperação e a solidariedade, sendo expressões de reciprocidade, também o são de justiça, porque implicam a preocupação pelo bem estar de todos e de cada um. Os princípios éticos distinguem-se das convenções, normas e leis. Enquanto a moral convencional depende das regras definidas pelas autoridades, visando a coesão do sistema e a perpetuação da ordem, a moral, pós-convencional assenta na defesa de princípios universais que são independentes das circunstâncias e da geografia.

O homem tem por essência conhecer e querer, emitir juízos de valor e, fazer escolhas de acordo com as suas preferências, tomar decisões, respeitar ou não uma norma convencional, agir conforme sua vontade, muitas vezes não respeitando a do seu próximo.

As pessoas sempre almejam alguma coisa que consideram importantes para si. Todo querer pressupõe um valor. Nesse sentido valora-se mais ou menos as diversas coisas que se nos deparam, seja através de juízos de valor positivo ou negativo. Normalmente as coisas que os homens consideram valiosas, são aquelas que está de conformidade com os seus interesses, independentemente de seu valor econômico, sendo que esse mesmo bem, para um terceiro, poderá não ter valor nenhum.

Chaui (1995, p.335- 336 passim), nos ensina de uma forma clara e prática o que é Juízo de valor: Se dissermos: Está chovendo, estaremos enunciando um acontecimento constatado por nós e o juízo proferido é um juízo de fato. Se, porém, falarmos, a chuva é boa para as plantas ou A chuva é bela, estaremos interpretando e avaliando o acontecimento, proferimos um juízo de valor. Esclarece-nos ainda que, juízos de valor avaliam, pessoas, ações, experiências, acontecimentos, sentimentos, estados de espírito, intenções e decisões como bons e maus, desejáveis ou indesejáveis. Os juízos de valor são também normativos, isto é, enunciam normas que determinam o dever ser de nossos sentimentos, nossos atos, nossos comportamentos. São juízos que enunciam obrigações e avaliam intenções e ações segundo o critério do correto e do incorreto. Os juízos éticos de valor nos dizem o que são o bem, o mal, a felicidade. Os juízos éticos normativos nos dizem que sentimentos intenções, atos e comportamentos devemos ter ou fazer para alcançarmos o bem e a felicidade. Os valores éticos se oferecem, portanto, como expressão e garantia de nossa condição de sujeitos, proibindo moralmente que nos transformem em coisa usada e manipulada por outros.

Para Reale (1974, p.38):

O certo é que toda norma enuncia algo que deve ser, em virtude de ter sido reconhecido um valor como razão determinante de um comportamento declarado obrigatório. Há, pois, em toda regra um juízo de valor, cuja estrutura é esclarecer, mesmo porque ele está no cerne da atividade do juiz e do advogado. 
(ibidem) o conceito de juízo é: “O ato mental pelo qual atribuímos, com caráter de necessidade, certa qualidade a um ser, a um ente. Toda norma ética expressa um juízo de valor, ao qual se liga uma sanção, isto é, uma forma de garantir-se a conduta que, em função daquele juízo, é declarada permitida, determinada ou proibida."

Para Libório (1994, p.142):

"A vida humana contempla uma sucessão de juizos de valor. Entretanto, é essencial que se diferencie um juizo de "valor" de um juízo de "essência", pois estes últimos recaem diretamente sobre o objeto. As pessoas devem ser cautelosas ao emitirem juizos de valor, pois se o fizerem de forma desmedida, pode ocorrer que o apego a um determinado valor em detrimento de outros, resulte em aberraçôes éticas de difícil reparação. A regra de conduta criada espontaneamente pela consciência de cada pessoa, deve pautar-se sempre na observância de valores maiores a serem considerados. O aprendizado de determinada disciplina, além de contribuir para o enriquecimento de nossos conhecimentos, ajudam-nos a formar nossos valores individuais."

O aprendizado se faz através de duas fontes básicas: a transferência de conhecimentos entre indivíduos e a experiência individual que conduz a uma descoberta independente. O grande legado dos seres humanos, na adaptação da vida, é sem dúvida nenhuma, a linguagem. O processo educativo leva ao exercício da capacidade de aprender experiências que, agem sobre a mente ou sobre o físico.

Rogers (1997, p.433), em seu famoso livro “Tornar-se Pessoa”, uma coletânea dos seus mais importantes estudos, alinhou algumas experiências científicas que revelam as conquistas realizadas nos últimos tempos pela ciência do comportamento. O seu intuito é demonstrar como se ampliam as possibilidades de compreensão, previsão e controle da conduta humana. Vejamos uma experiência:

Além da influência das imagens as pessoas também são influenciadas por pessoas, ou seja, os professores podem influenciar seus alunos, através de sua conduta, modos de agir ou de se apresentar, muito embora o aluno não domine a disciplina que está aprendendo, mas sente quando o professor tem o domínio da mesma, diante de sua conduta docente e, suas características podem se aceitas ou rejeitadas.

Existem muitas variáveis no comportamento das pessoas. A ciência ainda não descobriu uma fórmula para que se determine um tipo de comportamento padrão.

Neste sentido, observa muito bem Rogeres (1997, p.318-319 passim), "Sinto que o único aprendizado que influencia significadamente o comportamento é o aprendizado autodescoberto, auto-apropriado." Quando se comunica uma experiência vivida, não significa que ela vai ser aceita pela outra pessoa. O que houve, na realidade, foi uma tentativa de despertamento, onde se vislumbrou novos horizontes, que poderá ser aceita ou não. Segundo Rogers o aprendizado em grupo é aquele que surte melhores resultados, "Sinto que é extremamente compensador aprender, em grupo, nas relações com outra pessoa, como na terapia, oupor mim mesmo."

Os educadores entendem que a aprendizagem é facilitada quando o conteúdo se apresenta organizado ao aprendiz e que selecionar, organizar seqüenciado, articulando os conteúdos a serem ministrados são atividades importantes e, ao mesmo tempo as mais difíceis de serem praticadas na educação escolarizada. O educador colabora, quer queira ou não, para a formação dos valores de seus alunos.

Coll (1996, p.163-164)

"Valor é o princípio normativo que preside e regula o comportamento das pessoas em qualquer situação. Exemplos: o respeito à vida, à natureza, a solidariedade. Ensina-nos ainda que os valores concretizamse em normas, são regras de comportamento que as pessoas devem respeitar em determinadas situações: partilhar, ajudar, ordenar, respeitar e serem solidárias em casos de necessidades; acrescenta a isso tudo a atitude que é a tendência a comportar-se de forma consistente e persistente ante determinadas situações."

A formação do professor é de primordial importância e essa formação há de embasar-se na qualidade do ensino fundamental onde o professor acumulará ao seu conhecimento os valores adquiridos em sua formação básica. O que notamos, atualmente, é a minimização desses valores ou das habilidades necessárias. 
Makiguti (1994, p.142), afirma que: "Portanto os professores necessitam tanto de conbecimentos educacional especializado e universal, quanto de habilidades para lidar com o que quer que surja na prática. Tal domínio de teoria e de fins e meios só é alcançado com muitos anos de treinamentos e estudos."

Muitos professores não se especializam ou não se reciclam na disciplina que lecionam. Nessa falta, procuram usar o bom-senso, incorrendo em sérios erros e enganos, e o que é mais grave, tiram a motivação de seus alunos.

Hegenberg (1965, p.10), nos adverte: "O bom-senso é incompleto, deficiente. É função específica da ciência remover essa insuficiência, refinando concepsões comuns."

O professor, quando recorre ao bom-senso, tende a usar o conhecimento vulgar que é aquele adquirido superficialmente, por informações de terceiros ou experiência casual. A importância do conhecimento é que ele atinge os fenômenos em suas causas, caracterizando-se pela capacidade de analisar, de explicar, de desdobrar, de justificar, de aplicar leis e de predizer futuros eventos.

Nesse sentido Ruiz (1986, p 93) afirma: "O conbecimento cientifico nasce da dúvida e se consolida na certeza das leis demonstradas, enquanto o conbecimento vulgar normalmente gera incertezas desde o seu nascimento."

O professor que procura manter-se atualizado em sua disciplina, ampliando seus conhecimentos científicos, fazendo cursos e reciclando-se, ou seja, adequando-se ao momento atual, será merecedor de respeito e admiração por parte de seus alunos. Os costumes mudam e, como conseqüência, os valores da sociedade. As disciplinas de uma forma geral tendem a se ajustar de acordo com as mudanças da sociedade, dentro de um determinado espaço de tempo e de acordo com a nova realidade presente.

Luchesi (1986, p.83), afirma:

"O homem é um ser "datado e situado" bistoricamente. Pertence a um grupo, uma época, um povo. Possui, a partir de sua cultura a ambientação, determinada e especifica maneira de encarar a vida. Cria, neste contexto, seus princípios de vida, seus esquemas, suas estruturas, seus valores, seus interesses."

Conforme nos ensina ainda Luchesi (ibidem), a finalidade principal do conhecimento é proporcionar ao homem condições e possibilidades de uma avaliação crítica do seu modo pessoal e social de viver. Assim, o conhecimento se torna uma mola propulsora de mudanças e transformações sociais. Nenhum conhecimento é definitivo. Nenhum conhecimento é já exaustivo. Em realidade, todo e qualquer conhecimento que se obtém revela-nos uma faceta e um aspecto da realidade estudada.

Nem todo conhecimento é científico, ele pode ser popular, adquirido pela observação dos fenômenos que a natureza nos apresenta. Pode, ainda, ser transmitido pela gerações mais velhas às mais novas. O ser humano procura adaptar-se às circunstâncias, e às realidades que se apresentam no seu cotidiano. Vai, assim, adquirindo conhecimentos importantes que o ajudam a superar determinadas fases de sua vida.

Sendo a educação um processo colaborador para a humanização, considerada pelos autores como a "mola propulsora" da formação do caráter e, conseqüentemente dos valores das pessoas, estamos, ainda, distantes de um sistema educacional ideal. Quando o educador proporciona condições aos seus alunos, ou seja, condições adequadas à formação cidadã dos alunos, aproxima-se mais de um ensino eficaz, com melhores resultados. Sabemos também que certas medidas estão fora do alcance dos educadores, mas há muitas delas que são possíveis, desde que haja um consenso e que os limites estabelecidos de comum acordo sejam respeitados. Nosso sistema educacional ainda não encontrou uma forma adequada. Nesse sentido conclui Saviani (1994, p.94). “...pela inexistência de um sistema educacional no País, apontando apenas a existência de estruturas desarticuladas."

Destaca-se a necessidade de os educadores elaborarem uma teoria educacional a partir da práxis e que tal teoria seja capaz de servir de base para a construção de um sistema educacional de acordo com a nossa realidade.

Existem na teoria as mais variadas formas de pedagogia, Cotrim (1987, p.41-42 passim), nos apresenta algumas:

A pedagogia tradicional é um tipo de educação de conformidade com os padrões dominantes, ou seja, transmitem-se os padrões culturais preestabelecidos, permitindo a permanência das conquistas das classes dominantes.

A pedagogia renovada caracteriza-se de uma forma "mais livre". Permite mais a participação dos atores e da visão de cada um quanto ao futuro. Na pedagogia tradicional, o professor transmite conhecimentos. Na pedagogia renovada, os alunos e o professor estabelecem uma relação interpessoal harmoniosa.

Durante os anos do regime militar, no Brasil, ou seja, de 1964 a 1985, tivemos a pedagogia tecnicista que enfatizava 
mais a racionalização dos resultados e o controle dos objetivos educacionais. Essa pedagogia deixou marcas profundas que, se estendem até os dias de hoje. Segundo a pedagogia tecnicista, aprender é uma questão de modificação do desempenho, ou seja, a motivação, retenção e transferência decorrem da aplicação do comportamento operante. $\mathrm{O}$ aluno aprende com base técnica e responde através de um condicionamento das respostas que se quer obter.

Tendo em vista as limitações e insuficiências das correntes pedagógicas acima referidas, vem ganhando espaço e consistência a proposta da pedagogia dialética que vem surgindo como uma tentativa de superação dos impasses educacionais anteriores. Vejamos algumas características da nova pedagogia:

A palavra dialética vem do grego dialektikéé, significa a arte do diálogo, do debate, da discussão. Para Cotrim (1987, p.65), "servia para designar, na Antiguidade Clássica, o método de argumentação utilizado por filósofos como Sócrates (469-399 a.C.) e Platão (427-347 a.C.)." Esses filósofos viviam na busca incessante da verdade e, o choque de idéias, servia para desvendar através do raciocínio a busca da verdade procurada, em suas lições afirmam que, os princípios básicos da dialética, são os seguintes:

Tudo se relaciona: Nada acontece por acaso. Existe uma relação social ou natural interligando os fatos que os abrangem. Não se encontra justificativa para o estudo de um fato isolado. Temos que assumir uma visão real de conjuntos.

Tudo se transforma: Quando perguntaram ao genial Albert Einstein como ele definia a vida, o cientista respondeu com estas sintéticas palavras: "Algo se move". Estas palavras estão em sintonia com a dialética que afirma a realidade não como um sistema estático, imóvel, parado, mas como um sistema dinâmico, com interligações e, constante e permanente movimentação. Onde existe movimento, existe também transformação. O pensamento dialético exige um senso critico bastante apurado e permanente adequação entre a avaliação teórica e a prática correspondente.

Mudanşas qualitativas: As mudanças na dialética não são necessariamente lentas e insignificantes. Elas podem assumir ritmos que passam dos períodos lentos, quando sucedem pequenas alterações, por períodos acelerados, precipitando acelerações rápidas e constantes, dando saltos radicais, quando se trata de modificações consideradas básicas.

Lutas dos contrários: $\mathrm{O}$ motor fundamental da dialética consiste na luta incessante dos elementos contrários. Essas manifestações contrárias ocorrem através das contradições internas que se fazem presentes em todas as situações, na medida em que só nos é permitido a pensar no velho. A realidade é que somos sempre assaltados de temor, quando ocorre uma mudança radical. A luta dos contrários conduz a uma superação progressiva das contradições obedecendo aos seguintes critérios: A tese produzirá uma antitese e esta, por sua vez, produzirá uma sintese que, irá se constituir numa nova Tese, desencadeando, pois, novas contradições.

A educação escolar deve ser vista como um todo e não pode ser analisada separadamente, ou seja, isolada da realidade, tendo em vista a sociedade que a compõe. A pedagogia dialética rejeita as posturas do romantismo ingênuo ou do negativismo imobilista. Ela é dinâmica e permite constante diálogo, conforme as modificações no comportamento da sociedade como um todo.

O romantismo ingênuo promove uma justiça social injusta. O negativismo imobilista, por sua vez, reduz a escola à condição de comitê permanente de classes dominantes. A dialética é concebida como um dos espaços de lutas e conflitos dentro da sociedade capitalista por aqueles que desejam a sua transformação. Gadotii apud Lefebvre (1995, p.137), afirma que: "Na teoria dialética do conhecimento, o saber é um fato prático, social, portanto inacabado, em formação e reformulado no próprio dialogo do conhecer."

Na realidade, a dialética não é um conjunto de dados tratados e sistematizados, prontos para serem consumidos. Essa teoria se constrói no trabalho, onde o homem transforma e recria o mundo.

O professor encontra na sala de aula alunos de diferentes níveis sociais e é necessário compreender a dimensão de cada um. O grande desafio nas relações interpessoais é conseguir transmitir os conteúdos das disciplinas, levando-se em consideração as atitudes e os valores que eles trazem consigo. Em "Parâmetros Curriculares" (1997, p.44), lê-se a seguinte afirmação: "A aprendizagem de valores e atitudes é pouco explorada do ponto de vista pedagógico. Há estudos que apontam a importância da informação como um fator de formação e transformação de valores e atitudes"

O professor, ao se relacionar com o aluno, vai perceber que o mesmo traz consigo uma "bagagem", resultado do meio e dos costumes adquiridos na comunidade em que vive e em seu trabalho; incluirá questionamentos positivos, propondo mudanças, buscando construir, juntos, situações que potencializem sua capacidade intelectual, possibilitando seu aprendizado e, ainda, buscando uma maior capacitação de suas potencialidades interiores.

Em "Parâmetros Curriculares" (ibidem) lemos a seguinte observação: "A escola deve ser um lugar onde os valores morais são pensados, refletidos, e não meramente impostos ou frutos do bábito - A escola deve ser o lugar onde os alunos desenvolvam a arte do 
Existem diversos motivos que levam o indivíduo a aprender ou a modificar o seu comportamento. É necessário que se acrescente a essas aspirações a motivação, pois, como haveria o aluno de chegar ao resultado desejado se ele ignora, praticamente, em que consiste e para que consiste o seu aprendizado? O educador nem sempre se apercebe suficientemente dessa evidência de que, o aluno tem uma aspiração maior e, deseja ter uma idéia clara do resultado que quer atingir.

É importante que a pessoa, desde a infância, seja educada para construção de valores. As atividades de educação para o trânsito receberam indicações na nova legislação, Lei 9.503/97, artigo 19, inciso XV, que diz textualmente: "promover, em conjunto com os órgãos competentes do ministério da Educação e do Desporto, de acordo com as diretrizes do CONTRAN, a elaboração e a implementação de programas de educação de trânsito nos estabelecimentos de ensino."

Não temos até o momento a elaboração de programas para a educação no trânsito na pré-escola e nas escolas de $1^{\circ}, 2^{\circ}$ e $3^{\circ}$ graus. O que está sendo feito (quando é feito) é de forma tímida e esporádica, conforme o critério de cada escola. Temos oficialmente a "Semana Nacional de Trânsito", conforme estabelecido na nova lei de trânsito no final do artigo 75 e que está sendo cumprido pelas nossas autoridades de trânsito.

Na elaboração de programa de educação para o trânsito, deve-se levar em consideração a diversidade dos níveis culturais das pessoas, pois serão, das mais variadas camadas sociais. Daí a importância de técnicas pedagógicas participativas, voltadas para todos. Pois, sobre esses ensinos, terão os professores responsabilidade de contribuir para o processo de internalização dos valores, ensinar a conviver de uma forma saudável com o trânsito, primando por uma postura de atitudes corretas, com respeito às Normas estabelecidas na presente Legislação e defendendo sua cidadania, uma vez que o automóvel, é um signo que gera hegemonia de um segmento social sobre o outro, maiores leitos carroçáveis, menores calçadas, pois, o espaço físico das vias é sempre o mesmo e a tendência do número de veículos são aumentar a cada dia que passa. A formação do docente, sua cultura geral é base fundamental para o tratamento das questões urbanas, da cidadania, como é o caso da educação para o trânsito.

\section{REFERÊNCIAS BIBLIOGRÁFICAS}

BOCKENSKI, J.M. Diretrizes do pensamento filosófico. (trad. Alfred Simon).São Paulo: Editora Nacional, 1977.

BRASIL, Código de Trânsito Brasileiro. Lei 9.503, de 23 de setembro de 1997. Rio de Janeiro: ETJ - Equipe TécnicoJurídica, 1998.

CHAUI, Marilena. O que é ideologia. São Paulo: Atlas, 1995.

COLL, César. Psicologia e currículo. São Paulo: Ática, 1996.

COTRIN, Gilberto. Educação, para uma escola democrática. São Paulo: Saraiva,1987.

DINIZ, Maria Helena. Dicionário Jurídico. São Paulo: Saraiva, 1998.

GADOTTI, Moacir. Pensamento pedagógico brasileiro. São Paulo: Ática, 1995.

HEGENBERG, Leônidas H.B. Introdução à filosofia da ciência. São Paulo: Herder,1965.

HUBERMAN, A. M. (Trad. Por Jamir Martins). Como se realizam as mudanças em Educação. Subsídios para o estudo do problema da inovação. São Paulo: Editora Cultrix, 1973.

LUCHESI, Cipriano Carlos. Filosofia da educação. São Paulo: Cortez. 1986.

MARQUES, Ramiro. Escola, curriculo e valores. Lisboa: Rolo \& Filhos, 1997.

MARIKUTI, T. Educação para uma vida criativa. Rio de Janeiro: Record, 1994.

PENTEADO, W. M. A. (Org.) Psicologia e ensino. São Paulo: Papelivros, 1980.

REALE, Miguel. Lições preliminares de direito. São Paulo: Editora Jurídica José Bushatsky, 1974. 
ROHDEN, Humberto. Educação do homem integral. São Paulo: Parma, 1988.

ROGERS, Carl R. Tornar-se pessoa. (trad. Por Manuel José do Carmo Ferreira e Alvamar Lamparelli). São Paulo: Martins Fontes, 1997.

RUIZ, J. A. Metodologia Científica: Guia para eficiência nos estudos. São Paulo: Atlas, 1986.

ROZESTRATEN, Reinier J. A. Psicologia do trânsito. São Paulo: Editora da Universidade de São Paulo, 1988.

SANT'ANNA, Flávia Maria. ENRICONE, Délcia. ANDRÉ, Lenir Cancella, et al. Planejamento de ensino e avaliação. Porto Alegre: Sagra DC-Luzzato, 1992.

SAVIANI, Neide. Saber escolar, currículo e didática. São Paulo: Cortez, 1994.

WEBER, Max. Economia Y Sociedad: México: Fundo de Cultura Econômica. 1974. 
